\title{
Instrument to evaluate the behavioral intention of hypertensive people when taking anti-hypertensives
}

\author{
Instrumento para avaliar intenção comportamental de hipertensos de tomar os anti-hipertensivos \\ Instrumento para evaluar la intención del comportamiento de hipertensos de tomar los antihipertensivos
}

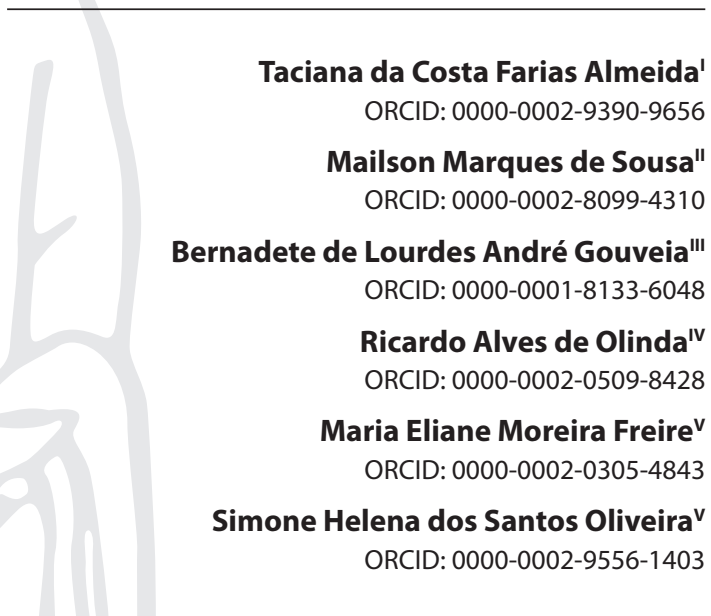

'Universidade Federal de Campina Grande. Campina Grande, Paraíba, Brazil. "Hospital Municipal Santa Isabel. João Pessoa, Paraíba, Brazil.

"'Universidade Federal de Campina Grande. Cuité, Paraíba, Brazil.

"Universidade Estadual da Paraíba. Campina Grande,

Paraíba, Brazil.

vUniversidade Federal da Paraíba. João Pessoa, Paraíba, Brazil.

How to cite this article:

Almeida TCF, Sousa MM, Gouveia BLA, Olinda RA, Freire MEM, Oliveira SHS. Instrument to evaluate the behavioral intention of hypertensive people when taking anti-hypertensives. Rev Bras Enferm. 2021;74(1):e20200192. doi: http://dx.doi.org/10.1590/0034-7167-2020-0192

Corresponding author:

Taciana da Costa Farias Almeida E-mail:tacianacfalmeida@gmail.com

EDITOR IN CHIEF: Antonio José de Almeida Filho ASSOCIATE EDITOR: Álvaro Sousa

Submission: $05-01-2020$

Approval: 08-04-2020

\section{ABSTRACT}

Objectives: to build and analyze the validity of an instrument to assess the behavioral intention of individuals with hypertension to take antihypertensive pills. Methods: methodological study based on the theory of planned behavior, developed in three stages: preparation of the instrument, validation of content and pre-test with the target audience. The content has been validated by six experts. The Content Validity Index was applied. Results: five nurses and one psychologist participated, with experiences in systemic arterial hypertension and/ or planned behavior theory. The first version of the instrument contained 40 items. After analysis, the second version originated, with 36 items. 100\% agreement was obtained for the scope of the constructions. The pre-test showed clarity and understanding of the items by the target audience. Conclusions: the instrument is a reliable and innovative technological product for use in populations with systemic arterial hypertension and beliefs similar to those identified in the surveyed group.

Descriptors: Hypertension; Antihypertensive Agents; Surveys and Questionnaires; Validation Study; Behavior.

\section{RESUMO}

Objetivos: construir e analisar a validade de conteúdo de um instrumento para avaliar a intenção comportamental de indivíduos com hipertensão de tomar comprimidos antihipertensivos. Métodos: estudo metodológico fundamentado na teoria do comportamento planejado, desenvolvido em três etapas: elaboração do instrumento, validação de conteúdo e pré-teste com o público-alvo. O conteúdo foi validado por seis especialistas. Aplicou-se o Índice de Validade de Conteúdo. Resultados: participaram cinco enfermeiros e um psicólogo, com experiências em hipertensão arterial sistêmica e/ou teoria do comportamento planejado. A primeira versão do instrumento continha 40 itens. Após análise, originou-se a segunda versão, com 36 itens. Obteve-se concordância de $100 \%$ para abrangência dos constructos. O pré-teste evidenciou clareza e compreensão dos itens pelo públicoalvo. Conclusões: 0 instrumento configura-se um produto tecnológico confiável e inovador para utilização em populações com hipertensão arterial sistêmica e crenças semelhantes às identificadas no grupo pesquisado.

Descritores: Hipertensão; Anti-Hipertensivos; Inquéritos e Questionários; Estudo de Validação; Comportamento.

\section{RESUMEN}

Objetivos: construiry analizar la validez de contenido de un instrumento para evaluar la intención del comportamiento de individuos hipertensos de tomar comprimidos antihipertensivos. Métodos: estudio metodológico fundamentado en la teoría del comportamiento planeado, desarrollado en tres etapas: elaboración del instrumento, validez de contenido y pretest con el público objetivo. El contenido ha validado por seis especialistas. Se aplicó el Índice de Validez de Contenido. Resultados: participaron cinco enfermeros y un psicólogo, con experiencias en hipertensión arterial sistémica y/o teoría del comportamiento planeado. La primera versión del instrumento contenía 40 ítems. Después del análisis, se originó la segunda, con 36 ítems. Se obtuvo concordancia de $100 \%$ para inclusión de los constructos. El pretest evidenció claridad y comprensión de los ítems por el público objetivo. Conclusiones: el instrumento se configura un producto tecnológico confiable e innovador para utilización en poblaciones con hipertensión arterial sistémica y creencias semejantes a las identificadas en el equipo investigado.

Descriptores: Hipertensión; Antihipertensivos; Investigaciones y Cuestionarios; Estudio de Validez; Comportamiento. 


\section{INTRODUCTION}

Adherence to the pharmacological treatment of systemic arterial hypertension $(\mathrm{SAH})$ is associated with the intention to perform the behavior "taking the prescribed pills to control hypertension"(1).

Adherence to treatment is individual health-related behavior consisting of the degree to which a person takes the medicine according to recommendations agreed with a health care professional ${ }^{(2)}$. Although pharmacological treatment is an important recommended therapy for individuals with $\mathrm{SAH}$, at different levels of care, the literature points to low compliance due to different factors ${ }^{(3-4)}$. Therefore, to reveal modifiable factors, which can be contributory to the adhesion, should be the target of research that seeks to contain the advance of the disease and its complications in the population.

In this sense, studies based on behavioral theories have aimed at elucidating these elements ${ }^{(1,5)}$. Among the theoretical structures is the theory of planned behavior(TPB), which seeks to measure the behavior intention, which is considered the immediate predictor of action (behavior) ${ }^{(6)}$ and, going beyond that, aims to elucidate the factors that determine it.

Behavior is a function of the intention to act - i.e. to affect the behavior - and the perception of control over it. As one of the immediate antecedents of behavior, intention is determined by three variables and their respective beliefs: Attitude, formed by behavioral beliefs (advantages, disadvantages and evaluation of the consequences of performing the behavior); Subjective Norm, formed by normative beliefs (opinion of positive and negative social referents and the motivation to agree with their opinions); and Perceived Behavioral Control, conducted by control beliefs (facilities and difficulties perceived to perform the behavior) ${ }^{(6-7)}$. These variables constitute the predictor constructs of behavioral intention.

TPB allows the addition of other variables, among them the past behavior as a direct predictor of future behavior, since its action occurs before access to the intentions and thought of the individual. This construct, when added, can be combined with the other predictors to explain repetitive and habitual behaviors (frequency and how recent) ${ }^{(8-9)}$; from them, intentions are automatically recovered, with minimal cognitive effort, and formed through the experience of actions over time - for example, taking the antihypertensive pills daily. Thus, it becomes relevant an instrument to measure the behavioral intention about the taking of anti-hypertensives in order to understand this variable as an important aspect to understand future behaviors ${ }^{(7,9)}$.

In line with the TPB theoretical assumptions, measurement instruments should be formulated based on salient beliefs about the behavior of interest (indirect measures), Attitude, Subjective Norm and Perceived Behavioral Control (measured directly) and the direct measurement of the intention to perform the behavior of interest $t^{(7,10)}$.

Faced with such understanding, a previous study was carried out with the objective of analyzing the beliefs of individuals with $\mathrm{SAH}$ in relation to the use of anti-hypertensives ${ }^{(11)}$ that would allow the identification of items for structuring instruments in line with the TPB recommendations, composed of direct and indirect measures, in order to favor the understanding of the behavior consistent with the context and beliefs of the population studied.

International studies that built TPB-based instruments, with a similar objective, also considered a specific questionnaire for the context. However, they used only direct measures addressing the TPB constructs (Attitude, Subjective Norm and Perceived Behavioral Control) to evaluate the determinants and behavioral intention related to the use of anti-hypertensives ${ }^{(1,12)}$.

In Brazil, a study is identified that integrates the development of a tool with theoretical support of TPB and addresses healthy behaviors in health according to both the beliefs issued by respondents $^{(13)}$ about past behavior ${ }^{(14)}$. However, research with the scope of evaluating the behavioral intention of individuals with SAH to take the antihypertensive pills was not found. Thus, the relevance of the study is justified by the fact that it conceives an instrument that integrates direct and indirect measures related to the behavior and extends the possibility of identifying the factors that determine it.

In addition, the use of a structured instrument based on beliefs that guide behavior will allow the identification, understanding and reflection on the psychosocial factors that determine the intention of taking anti-hypertensives for clinical control of SAH. In addition, it will indicate which variables need interventions to maintain or favor health protective behaviors.

\section{OBJECTIVES}

To build and analyze the validity of an instrument to assess the behavioral intention of individuals with hypertension to take antihypertensive pills.

\section{METHODS}

\section{Ethical aspects}

The development of the study met the national norms regarding ethics in research involving human beings and obtained the approval of the Research Ethics Committee of the Federal University of Campina Grande ${ }^{(15)}$. The consent of the participants and specialists was obtained by signing the Free and Informed Consent Term.

\section{Design, time and place of study}

Methodological development study ${ }^{(16)}$, carried out in three stages: construction of the instrument, content validation and pre-test with the target audience ${ }^{(15)}$. This study presents the stage regarding the theoretical pole of $\mathrm{TPB}^{(6)}$, developed from May 2018 to April 2019, in a public teaching hospital, located in the state of Paraíba, Brazil(15).

\section{Study protocol}

\section{Step 1: Construction of the measuring instrument}

It started with an extensive bibliographic survey on research that used TPB in the behavioral study on adherence to oral treatment of chronic diseases ${ }^{(1,5,17-19)}$. The TPB is a theoretical methodological reference from Social Psychology, which aims to support studies of health behaviors. This theory seeks to measure behavioral intention based on its determinants - Attitude, Subjective Norm and Perceived Behavioral Control ${ }^{(6)}$ — and allows the addition of variables in order to better understand the intention, among which is the past behavior ${ }^{(7,9)}$. 
According to the theory, the greater the behavioral intention, the greater the chances of the individual adopting the behavior. Therefore, to predict behavioral intention through its psychosocial variables, it becomes essential to survey beliefs, the starting point for the construction of the instrument for measuring behavioral intention, using salient modal beliefs - that is, those most emitted by participants in the study ${ }^{(7)}$.

Thus, the behavior of interest for the study was defined through the elements: action, target, context and time - in the next 30 days, taking prescribed tablets to control SAH. Delimited this behavior, a study was conducted among 28 individuals with $\mathrm{SAH}$, in a cardiology outpatient clinic in the Northeast region of Brazil, which identified the behavioral beliefs (advantages and disadvantages), normative (positive and negative social references) and control (facilities and difficulties) related to the behavior investigated ${ }^{(11,15)}$. After the survey, the beliefs were analyzed by issuing frequencies and content ${ }^{(6,10,20)}$. For TPB, beliefs guide the antecedent variables of behavioral intention.

Following this, the items of the instrument were formulated, consisting of direct measures to evaluate the construct more broadly, since they are easily understood; and by indirect measures, those formulated from the issued beliefs ${ }^{(10)}$. It should be noted that the wording of the items followed the recommendations of the TPB illustrative guide ${ }^{(20)}$ and the supporting material available for consultation on the homepage ${ }^{(21)}$ of the author of the theory.

The items of indirect measures were structured according to raised beliefs (behavioral, normative and control); and the direct measures, with items of more general approaches to behavior: Attitude, Subjective Norm, Perceived Behavioral Control and Behavioral intention. It was chosen to add the Past Behavior construct (frequency and self-reported recency of performing the behavior) - composed of a single item of direct measurement -, in which the respondent reports the frequency with which they perform a certain behavior in the last 30 days ${ }^{(8)}$, considering it a good future behavioral predictor, especially of habitual acts, such as the one studied.

In the first version, the instrument was made up of eight direct measurement items (one measure of behavioral intention, one of attitude, two of subjective norm, three of perceived behavioral control and one of past behavior) and 32 indirect measures (14 of attitude, being 7 of belief force and 7 for evaluation of consequences; 8 of subjective norm, being 4 of belief force and 4 of motivation to comply; and 10 of perceived behavioral control, being 5 of belief force and 5 of power to control)(15).

As a response option, the theoretical framework suggests a measurement scale composed of seven items ${ }^{(10,20)}$; However, a five-item scale was adopted in order to facilitate understanding and to circumvent possible difficulties, such as the low schooling of the target population studied. The scales used for direct measurement were of the Likert type and presented values ranging from 1 to 5 , with the indifferent point of " 3 ", and attributes that varied, in direct measurement items, from: very unlikely (1) to very likely (5); very unpleasant (1) to very pleasant (5); very harmful (1) to very beneficial (5); very useless (1) to very useful (5); and I totally disagree (1) to totally agree (5).

For indirect measures, the items presenting the issues of belief strength were also assigned on scales ranging from "very unlikely" (1) to "very likely" (5); and the items of consequence, motivation to comply/agree and power of control, on attributes ranging from "very bad" (1) to "very good" (5). Such attribute values were inverted in the questions that referred to the disadvantages and difficulties of carrying out the behavior under study.

\section{Step 2: Validation of content}

Content validation consists of the process of association between abstract concepts and measurable indicators and involves the analysis and judgment of specialists who examine the relevance of the statements for the proper representation of the contents addressed by the instrument ${ }^{(16,22-23)}$. Initially, the selection and invitation of specialists was made through the survey of curricula on the Lattes Platform. The inclusion criteria were: to be a nurse or psychologist; to have a doctor's and/or master's degree in health; to have experience (clinical, teaching or research) with SAH and/or TPB; and to have an article published in an indexed journal in the areas mentioned above. After the survey, based on the inclusion criteria, invitations were sent via e-mail to 11 experts in May 2018. With the acceptance by six of them, the instrument was sent via email in Microsoft Word ${ }^{\circ}$ format, containing the instructions on how to proceed with the analysis, and 15 working days for the return of the instrument with the analysis and suggestions. All experts who accepted to participate returned their analyses in the agreed time.

Experts were asked to evaluate: the constructs as to their comprehensiveness (check that each construction was adequately covered by the set of items); their items as to their clarity (assess whether the concepts were written in an understandable manner and appropriate to what was expected to be measured); and their relevance or representativeness (note whether the items reflected the concepts involved and were relevant and appropriate to achieving the proposed objectives) ${ }^{(23-24)}$. The 4-point Likert scale was used, ranging from "not relevant/unclear/representative" (1) to "relevant/clear/representative" (4) for each formulated item.

\section{Step 3: Application of the instrument in the pre-test}

After the experts' evaluation, the instrument was revised by the researchers, with some items being excluded and others reformulated or maintained according to the suggestions and comments, which originated the second version of the instrument. Reviewed by three TPB scholars from the Study Group on Chronic Diseases of the Federal University of Paraíba (GPDOC/UFPB) ${ }^{(15)}$, it was later submitted to the evaluation of the target audience as to the appearance and understanding of the items ${ }^{(24)}$. For this phase, 30 people with $\mathrm{SAH}$, over 18 years, participated in continuous use of oral anti-hypertensives for at least six months and in outpatient follow-up. The participants were approached for convenience and invited to evaluate the instrument in relation to the identification of words, inappropriate issues or issues difficult to understand. The understanding of the items was assessed in terms of clarity, context and length of the questionnaire related to the number of items.

\section{Analysis of results and statistics}

For content validity, in the instrument's analysis stage, the Content Validity Index (CVI) was used ${ }^{(23-24)}$. The $\mathrm{CVI}$ was calculated by adding together the number of items scored " 3 " or " 4 " divided by the total number of responses. To classify the item being evaluated as valid, 
the $\mathrm{CVI}$ was considered $\geq 0.8$. The items that obtained $\mathrm{CVI}<0.8$ were excluded and/or revised according to the experts' suggestions and subsequently evaluated by the target audience, originating the validated version of the questionnaire concerning its content ${ }^{(15)}$. In the on-screen study, to evaluate the scope of the constructs, the concordance criterion was used, obtained by dividing the number of participants who agreed by the total number of participants, multiplied by 100 . The instrument was considered validated if at least $90 \%$ of the respondents agreed ${ }^{(24)}$.

\section{RESULTS}

Six specialists participated in the questionnaire content validation stage: five nurses and a psychologist. All had a doctoral degree, five worked in teaching and research and three in assisting people with hypertension; three had experience with hypertension and planned behavior theory; one only with Theory of planned behavior and two with hypertension; five resided in the Southeast region and one in the Northeast region.

The initial instrument had 40 items. After the expert evaluation stage, there was consensus on the exclusion of four items $(18 ; 28 ; 33 ; 38)$, remaining 36 items in the final version of the instrument $^{(15)}$ (Chart 1).

In the general evaluation of the instrument, the agreement among the specialists was $100 \%$ for the scope of the constructs. Considering the CVIs $\geq 0.80$ attributed and the fulfillment of the recommendations, no second analysis by the specialists was necessary.

Chart 1 - Description of expert comments/suggestions, modifications and concordances for the criteria of clarity and relevance of the constructed items, Campina Grande, Paraíba, Brazil, 2019

\begin{tabular}{|c|c|c|c|c|c|}
\hline \multirow{2}{*}{ Items } & \multirow{2}{*}{ Comments/ Suggestions from the experts } & \multicolumn{2}{|c|}{ CVI } & \multirow{2}{*}{ Modified } & \multirow{2}{*}{$\begin{array}{l}\text { Final } \\
\text { Item }\end{array}$} \\
\hline & & CL & $\mathbf{R R}$ & & \\
\hline 1 & Add "I took all the pills" & 1.0 & 1.0 & Yes & Q1 \\
\hline 2 & Add "I took all the pills" & 1.0 & 0.83 & Yes & Q2 \\
\hline 3 & Add "I took all the pills" & 1.0 & 1.0 & Yes & Q3 \\
\hline 4 & Add "I took all the pills" & 1.0 & 1.0 & Yes & Q4 \\
\hline 5 & Add "I took all the pills" & 1.0 & 0.83 & Yes & Q5 \\
\hline 6 & Add the symptoms of the disease mentioned in the belief survey: headache, leg pain or nausea & 0.83 & 0.83 & Yes & Q6 \\
\hline 7 & Add "I took all the pills" & 1.0 & 1.0 & Yes & Q7 \\
\hline 8 & $\begin{array}{l}\text { Add the unpleasant symptoms mentioned in the belief survey: malaise, agony, stomach pain, } \\
\text { decreased libido, irritability, going to the bathroom several times or coughing }\end{array}$ & 1.0 & 0.83 & Yes & Q8 \\
\hline 9 & Restructure the item to clarify the term "dependent" & 0.83 & 0.67 & Yes & Q9 \\
\hline 10 & Add "I took all the pills" & 1.0 & 1.0 & Yes & Q10 \\
\hline 11 & Add "I took all the pills" & 0.83 & 1.0 & Yes & Q11 \\
\hline 12 & Add "I took all the pills" & 1.0 & 0.83 & Yes & Q12 \\
\hline 13 & Add the symptoms of the disease mentioned in the belief survey: headache, leg pain or nausea & 0.83 & 1.0 & Yes & Q13 \\
\hline 14 & Add "I took all the pills" & 0.83 & 1.0 & Yes & Q14 \\
\hline 15 & $\begin{array}{l}\text { Add the unpleasant symptoms mentioned in the belief survey: malaise, agony, stomach pain, } \\
\text { decreased libido, irritability, going to the bathroom several times or coughing }\end{array}$ & 0.83 & 1.0 & Yes & Q15 \\
\hline 16 & Restructure the item to clarify the term "dependent" & 0.83 & 0.83 & Yes & Q16 \\
\hline 17 & Add "take all pills" & 1.0 & 1.0 & Yes & Q17 \\
\hline 18 & Exclude the item by the extension of the instrument & 1.0 & 1.0 & Excluded & - \\
\hline 19 & Add "take all pills" & 1.0 & 1.0 & Yes & Q18 \\
\hline 20 & Add "take all pills" & 1.0 & 1.0 & Yes & Q19 \\
\hline 21 & Add "take all pills" & 0.83 & 1.0 & Yes & Q20 \\
\hline 22 & Add "take all pills" & 0.83 & 1.0 & Yes & Q21 \\
\hline 23 & Add "take all pills" & 1.0 & 1.0 & Yes & Q22 \\
\hline 24 & Add "take all pills" & 0.83 & 1.0 & Yes & Q23 \\
\hline 25 & Add "take all pills" & 0.83 & 1.0 & Yes & Q24 \\
\hline 26 & Add "take all pills" & 0.83 & 1.0 & Yes & Q25 \\
\hline 27 & No suggestions or comments & 1.0 & 1.0 & No & Q26 \\
\hline 28 & Exclude the item by the extension of the instrument & 0.83 & 1.0 & Excluded & - \\
\hline 29 & No suggestions or comments & 0.83 & 0.83 & No & Q27 \\
\hline 30 & Suggestions regarding the item rewrite & 0.83 & 0.83 & Yes & Q28 \\
\hline 31 & Add "take all pills" & 0.83 & 0.83 & Yes & Q29 \\
\hline
\end{tabular}


Chart 1 (concluded)

\begin{tabular}{|c|c|c|c|c|c|}
\hline \multirow{2}{*}{ Items } & \multirow{2}{*}{ Comments/ Suggestions from the experts } & \multicolumn{2}{|c|}{ CVI } & \multirow{2}{*}{ Modified } & \multirow{2}{*}{$\begin{array}{l}\text { Final } \\
\text { Item }\end{array}$} \\
\hline & & CL & $\mathbf{R R}$ & & \\
\hline 32 & Suggestions regarding the item rewrite & 0.83 & 0.83 & Yes & Q30 \\
\hline 33 & $\begin{array}{l}\text { Suggestion to exclude item related to the difficulty referred to as "forgetfulness", since the TPB } \\
\text { establishes rational and conscious decisions for the practice of behaviors }\end{array}$ & 0.83 & 0.83 & Excluded & - \\
\hline 34 & Add "buy all pills" & 0.83 & 1.0 & Yes & Q31 \\
\hline 35 & Add "all pills" & 0.83 & 1.0 & Yes & Q32 \\
\hline 36 & Suggestions regarding the item rewrite & 1.0 & 1.0 & Yes & Q33 \\
\hline 37 & No suggestions or comments & 0.83 & 1.0 & Yes & Q34 \\
\hline 38 & $\begin{array}{l}\text { Suggestion to exclude item related to the difficulty referred to as "forgetfulness", since the TPB } \\
\text { establishes rational and conscious decisions for the practice of behaviors }\end{array}$ & 0.83 & 0.83 & Excluded & - \\
\hline 39 & Add "all pills" & 0.83 & 1.0 & Yes & Q35 \\
\hline 40 & Suggestions regarding the item rewrite & 0.83 & 0.83 & Yes & Q36 \\
\hline
\end{tabular}

Note: CL - Clarity of Language; PR - Relevance and Representativeness; CVI - Content Validity Index; TPB - Theory of Planned Behavior.

To calculate the scores for each construction, the score for the direct measurements is obtained by averaging the values assigned on the Likert type scale, whose scores range from 1 to 5 (Past Behavior, Attitude, Subjective Norm, Perceived Behavior Control and Behavior Intent). For indirect measures, the scores are obtained by the model proposed by the theory: Behavioral beliefs (strength of belief $x$ evaluation of consequences), with scores ranging from 55 to 127; normative beliefs (strength of normative beliefs $\times$ motivation to agree with the referent), from 08 to 100 ; and Control Beliefs (strength of control $\times$ power of control), from 28 to 76 . It should be noted that there is no defined cut-off point; therefore, the higher the score obtained, the greater the influence of the variables on the intention to perform the behavior ${ }^{(6,10,20,25)}$ (Chart 2).

After expert analysis and restructuring in response to the suggested recommendations, the instrument was named QInTComHAS-36 and submitted to the pre-test with the target audience to assess the understanding and clarity of the items formulated. Participated 30 individuals with $\mathrm{SAH}$; mean age of $49.5 \pm 12.3$ years; female gender, 22 (73.3\%); mean monthly income per family of $R \$$ 3,074; brown skin color, 13 (43.3\%); married, 18 (60\%); residents with family members, 26 (86.7\%); workers with attachment, 12 (40\%); and complete elementary education, 13 (43.2\%). The average time to respond to the instrument was 14 minutes.

After reading the instrument and filling in the answers, the participants were asked about the understanding of the items and clarity of the written words. Some of the lines referred to the ease of answering the instrument, as it is understandable and presents clarifying information and questions that are easy to answer. Only one person mentioned the extent of the instrument by the large number of items, but there were no suggestions or recommendations for changes. Thus, the instrument was not modified, and respondents found the items formulated clear and understandable.

Chart 2 - Product distribution and probable scores per instrument construction Questionnaire Intention to Take Tablets for Systemic Hypertension (QInTComHAS-36), Campina Grande, Paraíba, Brazil, 2019

\begin{tabular}{|c|c|c|c|}
\hline Construct & Variables & Semantic adjectives & Probable scores \\
\hline Past behavior & Direct measure $\left({ }^{*} \mathrm{Q} 1\right)$ & $\begin{array}{c}\text { I totally disagree / I totally agree } \\
\text { No day/all days }\end{array}$ & $1-5$ \\
\hline \multirow{4}{*}{ Attitude } & Direct measure (Q2) & $\begin{array}{l}\text { Very unpleasant/Very pleasant } \\
\text { Very harmful / Very beneficial } \\
\text { Very useless/Very useful } \\
\text { Very easy / Very difficult }\end{array}$ & $1-5$ \\
\hline & Indirect m & & \multirow{3}{*}{$55-127$} \\
\hline & Behavioral beliefs (Q3-Q9) & Very unlikely/very likely & \\
\hline & Evaluation of the consequences (Q10-Q16) & Very bad / Very good & \\
\hline \multirow{4}{*}{ Subjective Norm } & Direct measure (Q17) & I totally disagree / I totally agree & $1-5$ \\
\hline & Indirect m & & \multirow{3}{*}{$8-100$} \\
\hline & Normative belief (Q18-Q21) & Very unlikely/very likely & \\
\hline & Motivation to agree (Q22-Q25) & I totally disagree / I totally agree & \\
\hline \multirow{4}{*}{ Perceived Behavioral Control } & Direct measure (Q26-Q27) & I totally disagree / I totally agree & $1-5$ \\
\hline & \multicolumn{2}{|c|}{ Indirect measures } & \multirow{3}{*}{$28-76$} \\
\hline & Control Beliefs (Q28-Q31) & Very unlikely/very likely & \\
\hline & Power of the belief (Q32-Q35) & I totally disagree / I totally agree & \\
\hline Behavioral intention & Direct measure (Q36) & Very unlikely/very likely & $1-5$ \\
\hline
\end{tabular}

Note: Q - question. 


\section{DISCUSSION}

The choice of the theory of planned behavior ${ }^{(6)}$ as a theoretical methodological reference was fundamental to the process of construction of the instrument, by allowing its content to be categorized by means of a construction manual of the instrument with its own model, recognized internationally ${ }^{(10,21)}$. The use of this reference tool made it possible to contemplate the listed constructs in order to evaluate the determinants of the behavioral intention to take the prescribed pills to control SAH, as well as to insert the construct "past behavior"(9) in the structure of the instrument.

The method used for the development of the study allowed approximation with the reality of individuals affected by $\mathrm{SAH}$, through a survey of the scientific literature relevant to the subject and identification of the beliefs ${ }^{(11)}$. This fact contributed to the understanding of assistance processes involved in outpatient care, since the beliefs issued and inserted in the construction of the instrument were analyzed and discussed. For example, the difficulty encountered in adopting the behavior described as "forgetfulness", which is not part of volitional behavior, but is inherent to cognitive factors and age, difficult to measure, being asked for its exclusion by experts - two items: strength of belief (33) and power of control (38).

Although forgetfulness is an irrational and unconscious action, its understanding interferes with the ability to adhere to oral treatment of chronic diseases ${ }^{(1,11,26)}$. For this reason, forgetfulness should be analyzed by means of alternatives not based on TPB constructs, in order to propose interventions that minimize their effects on drug treatment adherence.

Regarding the Attitude construct, item 9 presented a CVI of 0.67. Because it was constructed based on behavioral belief, related to the disadvantage of "becoming dependent", of taking the drugs and based on studies ${ }^{(18-19,27)}$, as well as associating it with the low motivation to use medication for chronic disease control, the judges' suggestions were accepted; and the item, reformulated and kept in the instrument. It is understood that such belief requires attention from the health care team in order to clarify the chronic nature of hypertension and its severity when not treated adequately. In other words, it goes through, among other measures, the correct and consistent use of antihypertensives, with regular visits to the health service to adjust doses and follow up on non-pharmacological measures. Therefore, it is not about becoming dependent, but active in self-care and maintaining the quality of life.

The constructs Subjective Norm (SN) and Perceived Behavioral Control (PBC) had two items of direct measurements: items 18 and 28), which referred to "direct measurements of SN and PBC", respectively. The experts recommended their exclusion, with the argument that only one item would be sufficient to perform the direct measurement of these constructs, since the number of beliefs and indirect measurement items formulated would be enough to apprehend the object of investigation. Other measuring instruments with similar objectives ${ }^{(1,12)}$ included at least three items of direct measures in these constructions, but did not present indirect measures in their composition. When considering the experts' analysis and the scope of the instrument, it was decided to exclude items 18 and 28 and to value the beliefs obtained by indirect measures, which are the basis for the predecessors of behavioral intention.

Behavioral intention is considered an immediate indicator of behavior ${ }^{(6)}$. This indication is measured when individuals are directly asked if they want, plan, desire, expect to perform the behavior. The greater the intention, the greater the chances that individuals will have this behavior. In this instrument the following statement was considered:'I intend to take all my prescribed pills for hypertension control within the next 30 days"(Q36), with response range of "very unlikely" (1) to "very likely" (5). The experts' agreement for this item was 0.83 for clarity and pertinence, being reformulated only in relation to the writing suggestions.

With regard to the analysis of the index of agreement between specialists by means of the $\mathrm{CVI}^{(24)}$, the instrument has reached, in relation to items and constructs, indexes $\geq 0.80$ recommended for this type of analysis, being considered valid in relation to its content. The participation of nurses and psychologists with extensive professional experience, research within the adopted theoretical framework and assistance to individuals with hypertension was essential for the analysis of content. Such participation showed the commitment to the construction of knowledge in the areas that involved the elaboration of the instrument, understanding the importance and necessity of the study and its responsibility in this construction, becoming an effective participation for its improvement and validation.

The specialists involved considered that the constructs selected for the composition of the instrument were relevant and presented essential items to evaluate the determinants of the behavioral intention of taking the antihypertensive pills, when based on the TPB precepts, obtaining 100\% agreement between them. The selection and quantity of specialists can be judged appropriate ${ }^{(22)}$, considering a minimum number of five and a maximum of ten judges, added to the experience and qualification of the members involved in the areas of analysis of the items. It should be noted that other studies with theoretical support in TPB have also adopted content validation for the refinement of the formulated items ${ }^{(28-29)}$.

The ordering of the constructs, with regard to the presentation of the instrument, took place in accordance with a study that recommends the initial evaluation of the measure of past behavior, in relation to the measure of behavioral intention ${ }^{(9)}$. Since past behavior is a predictor construct of future acts and an independent variable of the measure of behavioral intention, its evaluation after measure of intention may induce responses. Thus, the subsequent application of this instrument by means of quantitative surveys, which allow the establishment of correlations between the independent variables and the dependent variable, is necessary to confirm this assumption.

Knowing the beliefs of individuals and elaborating an instrument directed to the clientele that lives with this pathology, performing this action on a daily basis, will make it possible to know psychosocial factors that may interfere with the performance of the behavior, as well as to subsidize interventions directed to attitudinal, normative, perceived control aspects. Furthermore, it will allow for the subsidization of interventions focused on the beliefs inherent to specific contexts in order to influence the consistent use of drug treatment for $\mathrm{SAH}$; that is, to adopt strategies based on the identification of the factors that 
determine the behavior in the target audience. Thus, in order to determine the intent of taking prescribed tablets to control $\mathrm{SAH}$ in the next 30 days and its predictive factors, QInTComHAS-36 has been constructed and validated for its content.

\section{Study limitations}

It should be noted that the incipiency of national and international studies addressing the construction and validation of an instrument, with the aim of assessing the behavioral intention of taking the prescribed tablets to control $\mathrm{SAH}$, has limited the comparative analysis of the results obtained in this research.

Empirical and analytical validations are steps still to be done, which confers some limitation to the results achieved so far. Research for this purpose is being developed by researchers to ascertain the overall reliability of the instrument.

\section{Contributions to the Nursing, Health or Public Policy area}

It is believed that this research brought contributions for the construction and validation of content of an instrument that aims to understand psychosocial factors involved in taking antihypertensive drugs, with a view to building a lightweight technology for assessing a Public Health problem within the Nursing and inter-professional team, involved in assisting the individual with
$\mathrm{SAH}$. Although the study was conducted at an outpatient care level, this does not prevent its application to other levels of care by staff committed to the care of this clientele. In other words, the health care of the individual with SAH occurs in health care networks, thus enabling its application in other levels of care.

As an innovative nursing care tool, this tool can be used in nursing consultations for individuals with hypertension, in specialized outpatient clinics and in the health care network. In this way, the nurse will understand the psychosocial factors that may motivate antihypertensive drug treatment or interfere with it, culminating in the proposition of intervention strategies to improve the self-management of this clientele's health.

\section{CONCLUSIONS}

This study allowed the construction and validation of an instrument that, after empirical and analytical validation, may support the identification of the determinants of the behavioral intention to take the prescribed pills, to control hypertension, with structuring based on the theoretical pole of TPB. The method used has proven adequate to achieve the proposed objective and may help to carry out other research related to the theme. The proposed instrument presented validity of content, which allows its application to individuals with SAH in the Health Care Network to ascertain its general reliability.

\section{REFERENCES}

1. Ho YC, Ho CP, Shih JH. Factors affecting medication compliance behavior among hypertension patients based Theory of Planned Behavior. Gen Health Med Sci[Internet]. 2015 [cited 2019 Jun 4];3(1):1-5. Available from: http://waprogramming.com/archive/Journals/General\%20 Health\%20and \%20Medical\%20Sciences/315233868-Factors-Affecting-Medication-Compliance-Behavior-among-Hypertension-Patientsbased-on-Theory-of-Planned-Behavior.pdf

2. Organización Mundial de la Salud (OMS). Adherencia a los tratamientos a largo plazo: pruebas para la acción [Internet]. Washington: OMS;2004[cited 2019 Jun 4]. 199 p. Available from: http://www.farmacologia.hc.edu.uy/images/WHO-Adherence-Long-Term-Therapies-Spa-2003.pdf

3. Martin LR, Feig C, Maksoudian CR, Wysong K, Faasse K. A perspective on nonadherence to drug therapy: psychological barriers and strategies to overcome nonadherence. Patient Prefer Adherence [Internet]. 2018 [cited 2019 Jun 4];12:1527-1535 Available from: https:// www.ncbi.nlm.nih.gov/pmc/articles/PMC6112807/pdf/ppa-12-1527.pdf

4. Barreto MS, Cremonese IZ, Janeiro V, Matsuda LM, Marcon SS. Prevalence of non-adherence to antihypertensive pharmacotherapy and associated factors. Rev Bras Enferm. 2015;68(1):60-67. doi: 10.1590/0034-167.2015680109p

5. Morrison VL, Holmes EAF, Parveen S, Plumpton CO, Clyne W, De Geest S, et al. Predictors of self-reported adherence to antihypertensive medicines: a multinational, cross-sectional survey. Value Health. 2015;18(2):206-16. doi: 10.1016/j.jval.2014.12.013

6. Ajzen I. The Theory of Planned Behavior: organizational behavior and human decision process.1991;2(50):179-211.doi: 10.1016/0749-5978(91)90020-T

7. Ajzen I. Constructing a TPB Questionnaire: conceptual and methodological considerations [Internet]. 2002[cited 2019 May 27]. Available from: http://www.apcc.online.pt/upload/membro.id/ficheiros/i005562.pdf

8. Cristo F, Günther H. Como Medir o Hábito? Evidências de Validade de um Índice de Autorrelato. Psicol Teor Pesqui. 2016;32(2):1-9. doi: 10.1590/0102-3772e322224

9. Ouellette JA, Wood W. Habit and intention in everyday life: the multiple processes by which past behavior predicts future behavior. Psychol Bull[Internet]. 1998 [cited 2019 Jun 4];124(1):54-74. Available from: https://pdfs.semanticscholar.org/1877/3d4fa2e3d187f17b387ef56e4fdf 6c1e8c15.pdF

10. Francis J, Eccles MP, Jonhston M, Walker AE, Grimshaw JM, Foy R, et al. Constructing questionnaires based on the theory of planned behavior: a manual for health services researchers[Internet]. Newclastle upon Tyne, UK: Centre for Health Services Research; 2004[cited 2019 May 20]. Available from: http://openaccess.city.ac.uk/1735/

11. Almeida TCF, Sousa MM, Pessoa MSA, Sousa LS, Gouveia BLA, Oliveira SHS. Beliefs of individuals with systemic arterial hypertension related to drug treatment. Rev Rene. 2019;20:e41585. doi: 10.15253/2175-6783.20192041585 
12. Bane C, Hughe CM, McElnay JC. Determinants of medication adherence in hypertensive patients: an application of self-efficacy and the Theory of Planned Behaviour. Int J Pharm Pract. 2006;14(3):197-204. doi:10.1211/ijpp.14.3.0006

13. Ferreira G, Pereira MG. Validation on the questionnaire of planned behavior on diabetes: physical activity. Psicol Saúde Doenças. 2014;15(2):409-26. doi: 10.15309/14psd150207

14. Moura LRC, Veiga RT, Cunha NRS, Moura LEL. The theory of planned behavior and their modification with the inclusion of the past behavior: a study on the behavior of trying to lose weight. Perspect [Internet]. 2012 [cited 2019 May 20];36(136):167-79. Available from: http://www. uricer.edu.br/site/pdfs/perspectiva/136_317.pdf

15. Almeida TCF. Determinantes psicossociais do uso de anti-hipertensivos orais: instrumento de medida e tecnologias motivacionais[Tese]. Universidade Federal da Paraíba, João Pessoa; 2019.

16. Polit DF, Beck CT. Fundamentos de pesquisa em enfermagem: avaliação de evidências para a prática da enfermagem. 9 ed. Porto Alegre: Artmed, 2019.456p.

17. Holmes EAF, Hughes DA, Morrison VL. Predicting to medications using health psychology theories: a systematic review of 20 years of empirical research. Value Health. 2014;17(8):863-76. doi: 10.1016/j.jval.2014.08.2671

18. Rich A, Brandes K, Mullan B, Hagger MS. Theory of planned behavior and adherence in chronic illness: a meta-analysis. J Behav Med. 2015;38(4):673-88. doi: 10.1007/s10865-015-9644-3

19. Pagés-Puigdemont N, Mangues MA, Masip M, Gabriele G, Fernández-Maldonado L, Blancafort S, et al. Patients' perspective of medication adherence in chronic conditions: a qualitative study. Adv Ther. 2016;33(10):1740-54. doi: 10.1007/s12325-016-0394-6

20. Fishbein M, Ajzen I. Predicting and changing behavior: the reasoned action approach. New York, NY: Routledge; 2015. 518p

21. Ajzen I. TPB Questionnaire Construction [Internet]. 2019[cited 2019 Jun 4]. Available from: https://people.umass.edu/aizen/pdf/tpb. measurement.pdf

22. Medeiros RKS, Ferreira Jr MA, Pinto DPS, Vitor AF, Santos VEP, Barichello E. Pasquali's model of content validation in the Nursing researches. Rev Enferm Ref.2015;4(4):127-35. doi: 10.12707/RIV14009

23. Souza AC, Alexandre NMC, Guirardello EB. Psychometric properties in instruments evaluation of reliability and validity. Epidemiol Serv Saude. 2017;26(3):649-59. doi: 10.5123/S1679-49742017000300022

24. Coluci MZO, Alexandre NMC, Milani D. Construction of measurement instruments in the area of health. Ciênc Saúde Colet. 2015;20(3):92536. doi: 10.1590/1413-81232015203.04332013

25. Ajzen I, Fishbein M. Scaling and testing multiplicative combinations in the expectancy-value model of attitudes. J Appl Soc Psychol. 2008;38(9):2222-47. doi: 10.1111/j.1559-1816.2008.00389.x

26. Gouveia BLA, Sousa MM, Almeida TCF, Sousa VAG, Pereira WDF, Oliveira SHS. Beliefs related to oral antidiabetic use among individuals with diabetes. Esc Anna Nery. 2020;24(1):e20190148. doi: 10.1590/2177-9465-EAN-2019-0148

27. Lokita AA, Mabuza LH, Okonta HI. Reasons given by hypertensive patients for concurrently using traditional and Western medicine at Natalpruit Hospital in the Gauteng Province, South Africa. Afr J Prm Health Care Fam Med. 2013;5(1):[7pages]. doi: 10.4102/phcfm.v5i1.458

28. Bai X, Wang A, Plummer V, Lam L, Cross W. Using the theory of planned behavior to predict nurse's intention to undertake dual practice in China: a multicentre survey. J Clin Nurs. 2019;28:2101-10. doi: https://doi.org/10.1111/jocn.14791

29. Gagnon MP, Cassista J, Payne-Gagnon J, Martel B. Applying the Theory of Planned Behavior to understand nurse intention to follow recommendations related to a preventive clinical practice. J Res Nurs. 2015;20(7):582-93. doi: 10.1177/17449887115611715 